\title{
Identification and Prioritization of the Factors Impacting the Social Responsibility of the Extractive Oil and Gas Industries
}

\author{
Mohammad Reza Abyar ${ }^{1}$ \& Hassan Rangriz ${ }^{1}$ \\ ${ }^{1}$ Department of Executive Management, Kermanshah Branch, Islamic Azad University, Kermanshah, Iran \\ Correspondence: Hassan Rangriz, Department of Executive Management, Kermanshah Branch, Islamic Azad \\ University, Kermanshah, Iran. Tel: 98-91-6614-4028. E-mail: hassanrangriz@gmail.com
}

Received: July 26, 2014 Accepted: September 27, 2014 Online Published: December 20, 2014

doi:10.5539/ass.v11n2p111 URL: http://dx.doi.org/10.5539/ass.v11n2p111

\begin{abstract}
Destruction of Ozone layer, increase of earth temperature and climate changes as a result of GHG (Green -House Gasses) are the most significant concerns of the society these days.

Since the gas and oil extractive industries can pollute the environment and there are many oil and gas installation near the residential areas, the expectations have to be attended and the local society should consider the limitations as the most challenging issues. This project has been done from Feb 2014 to June 2014 through questionnaires containing 49 effective factors based on the rules of ISO 26000 standards that have been distributed among top and middle managers. Finally the hypotheses have been evaluated by Pearson test based on the presence of a significant relationship between each of 7 variables and the social responsibility of the considered company and then the variables and their structural performances have been ordered by using Friedman test.
\end{abstract}

Keywords: social responsibility, stakeholders, ISO 26000

\section{Introduction}

\subsection{Definitions}

\subsubsection{Social Responsibility}

The responsibility of an organization in the case of decision-making and its impacts on the environment and society includes the following:

1) Participation in an sustainable improvement including health and welfare of the society

2) Consideration of the stakeholders and expectations

3) Accommodation with the roles and international behavioral norms

4) Integration of social responsibility in the whole organization and using its own relationships (Omidvar, 2012, p. 38)

\subsubsection{Sustainable Development}

It's a development which responds to the needs of future generations without compromising their abilities (Omidvar, 2012, p. 39).the sustainable development has 3 aspects including economic, social and environmental aspects that are related to each other and try to obviate the needs considering the local and environmental limitations but the social responsibility focuses on the organizations' social responsibility and its responsibility about these 3 aspects. Since the social responsibility and sustainable development has a close relationship they usually have been used interchangeably while they have different meanings.

\subsubsection{Stakeholders}

A person or a group of people who benefits from an organizational decision or activity is called a stakeholder. In the other words people or groups who may be affected by the decisions and activities of the company are called stakeholders. This effect may be negative or positive. 


\subsection{Definition of Companies' Social Responsibility}

The main idea about social responsibility identifies it as a humanitarian activity like helping charities. Topics like the company's performance and fair industry have been introduced about last century and then it became obvious that the social responsibility is applicable for all organizations and all companies that have some responsibilities to obtain development and that's why many different issues like human rights, environment, consumer supporting, corruption fighting and cheating have been added to that. The issues of ISO 26000 standard show the current ideas about desirable activities. The ideas may be changed in the future based on the correct methods so we have to consider other important issues in relation with social responsibility (Omidvar, 2012, p. 41).

The content of social responsibility of the organization has been changed to the dominant paradigm of the companies' management and valid and large corporations around the world consider the social responsibility and the social environment as a part of their strategy. This is a definition which many developing countries and countries with open economic like governments, corporations, civil societies, international organizations and scientific centers are looking for. There are many different ideas about the social responsibility as follow:

- The governments consider the social responsibility of the companies from the view of tasks, decisions, responsibilities and moving toward a sustainable development

- Companies consider the social responsibility of the corporations as a result of awareness about the financial standards and tragedies of corporates' performance

- since the effectiveness of these organizations in the current world is more than what can be seen in the governments international organizations, facing the challenges without corporates partnership seems impossible, because most of the politicians are the managers and expect the social responsibility of the companies

- The scientific centers and universities consider the social responsibility of the companies in a view of the role of companies in development of a country and its democracy and interference of the duties of a company with the government (Omidvar, 2012, p. 14)

\subsection{The Main Issues Related to Social Responsibility}

To determine the scope of social responsibility and its related issues the organization should consider the followings:

Organizational governance, human rights, working activities, environment, fair performing activities, consumers and customers-related issues, participation in local societies and their development (Omidvar, 2012, p. 73)

\subsection{Underlying Activities of Social Responsibility}

There are many issues included in ISO 26000 standard that are not being used by different organizations equally. So, it's the duty of the organization to consider the organizational considerations, talk to stakeholders, identify most important issues and prioritize the performing plans. For example, the social responsibility of the municipals, banks, hospitals, educational centers, charities, mosques and productive companies is different and it's important that manager's act based on the content of their activities, mission description, values and perspectives of the organization.

Before analyzing the main issues of the social responsibility and its related actions and expectations, the organization should consider the following underlying activities:

1. Identifying the social responsibility in the field of organizational influence

2. Identifying the stakeholders and participating with them after understanding the principles of social responsibility. Based on ISO26000 standard, the organization should look for a way to integrate the social responsibility in its own decisions and actions (Omidvar, 2012, p. 28)

\subsection{Problem Solving}

In the oil and gas extractive industries, consideration of social responsibility's different aspects is very important because of the followings:

1) Pollution of the oil and gas extraction activities

2) High level of performing activities' risks in the gas and oil extractive companies due to the deployment of oilfields, wells, gas and oil extractive installations and pipelines of gas and oil in the surrounding cities and towns.

3) High expectation level of stakeholders in the public gas and oil industries

However it's a very important issue but there has been no standard method used to identify the factors of social 
responsibility during production in the company impacting the stakeholders and other future generations directly and indirectly. In fact, the effective factors impacting the social responsibility are not determined clearly and their boarders are not determined as well, so it can't be said that how much and in which fields it can act. There is also no evidence to show what are the principles related to the social responsibility of the company and what should the company do to make its social responsibility performing? Are all the participles of ISO 26000 standards, related and compatible to the social responsibility of the company? Should the managers be responsible for all of the ISO 26000 standard provisions? And if it is so, then how should be the order of their performance?

\subsection{The Importance of the Research}

The social responsibility in the extractive gas and oil industry is important in the following aspects:

1) Placing the oil wells and gas and oil extractive installations near the residential area, airports, industrial units and other important places in the local society

2) Passage of gas and oil pipelines over the rivers, roads, rails, subways, rural and urban residential areas, agricultural lands and well lands

3) Under-state enterprises and high expectations of stakeholders and society

4) The obvious role of oil and gas extractive industries in the emission of gasses like carbon dioxide and increasing the temperature of the earth and changing the weather and destroying the ozone layer as the main and current concerns of people

5) The very effective role in development of local society from economic, cultural, and social aspects

6) Non-desirable weather and natural conditions as a result of the heat, pollution of other industrial units and the pollution made by performance of other oil and gas extractive industries which worsen the weather conditions

7) Need to institutionalize this humanitarian action in the structure of the organization voluntarily and performing activities related to social responsibility to participate in sustainable development

8) Need to make a peaceful coexistence between the working space of oil company and its surroundings

9) High purchase volume, manufacture, construction projects and the need to consider them

10) Need to use a standard pattern as a guide and appropriate measure for identifying different aspects of social responsibility, ordering multiple expectations and realizing the expectations and needs in an integrated and balanced manner

11) Possible use of appropriate approaches to answer the expectations of the stakeholders and reduce the current challenges

The studies show that considering the expectations of the stakeholders and making an appropriate interaction with them can decrease the risk level of the organizational performance and gain the support of the stakeholders that lead to benefits.

The is 26000 standard principles have been used to identify and order the field of social responsibility in the oil and gas extractive industries.

By using this research, the different aspects of social responsibility can be identified and understood clearly and act in the means of ordering, targeting, planning and completing its requirements.

The studies show that if the social responsibility has not been considered, many challenges would come up like:

1. Increasing limitations of environmental organizations on the organization of environmental crimes

2. High risks resulting from the small distance between the gas and oil installations and residential areas. Crossing of pipelines over the rivers, trains, and land, air, rail and communicational roads

3. Increase of managers trials

4. Disruption in the continuity of production and increase in the costs because of performing problems and the need for reducing the environmental pollution.

5. Increase in the conflicts with the local society because of the gas and oil pipelines passing over the agricultural lands and orchards

6. The force of local societies on employment, the force of local societies on obtaining the skills and local providers the social responsibility can affect different aspects of the company. So, by obtaining necessary knowledge and awareness and through appropriate management the environmental and organizational risks can 
be eliminated and a brighter future can be made.

\subsection{Purposes}

By considering the points that have been mentioned previously, the ISO 26000 standard and analyzing patterns of stakeholders have been used to identify the social responsibility and institutionalize the social responsibility to improve this important responsibility.

The purposes of this study are as follow:

1) Ideal purpose: improving the organizational share to participate in stable development

2) General purpose: identifying the factors impacting the social responsibility in different fields

3) Practical Purposes:

4) Social risk management through participation with local organizations and obtaining local license.

5) Improving the score in an Business Excellence Model to improve the condition of social responsibility evaluation

6) Integrating the current activities of the organizations in the field of social responsibility

\subsection{History of the Previous Studies}

\subsubsection{Researches in the Field of Social Responsibility around the World}

There are many articles that have been seen out of Iran. 3 examples of them are included here as follow:

- "A multidimensional approach for CSR assessment: The importance of the stakeholder Perception". This article was published by Roberta Costa \& Tamara Menichini (2013) in the systems with applications expert journal and science direct system. Based on the contents of the article, the level of understanding the stakeholders' expectations is one of the key issues in the evaluation of social responsibility. In this article, the GRI (Global Reporting Initiatives) has been used to analyze the BSC-based (Balance Score Card-based) social activities and responsibilities. In this article a multi-criteria approach has been used which is mixed with the phase variables and makes a hierarchy of social responsibility factors with the goal of integrating the dimensions and the strategic goals in the financial and non-financial fields. The hierarchy makes a multi- dimensional model which can evaluate the multi-dimensional social behavior in the company.

- Corporate Social Responsibility in the extractive industries Experiences from developing countries by Gavin Hilson (2012). It has been studied that how multinational companies of oil and gas industries face the challenges of social responsibility and how developing countries answer the claims about themselves. This article discusses the companies' social responsibility in the extractive industries and evaluates the important factors like risk management, supporting human sources, answering consumer wants and skipping the laws. The level of expectations from these industries is very high but the agreements try to support the social responsibility of the industries. So, there is a need to predict the laws and rules to make them more applicable.

- Corporate social responsibility and the oil industry: Theory and perspective fuel a longitudinal view by Ingrid \& Donnalyn Pompper (2011). In this article, 4 key suggestions are provided for developing the social responsibility including: 1. Responding to the social responsibilities from inside to out of the company, 2. Accepting trust of people and media, 3. Looking at it as a citizen, 4. Accepting that all of us are together and these factors are provided for oil industries

The above articles have evaluated the social responsibilities of oil and gas extractive industries and have studied the challenges and ways of their solving and they also have provided some suggestions for operating the social responsibility in the field of gas and oil extraction

\subsubsection{Studies Which Have Been Done in the Field of Social Responsibility in Iran}

Even though that the social responsibility is a very important issue among Oil and Gas extractive industries, there aren't any researches in this field.

Also there is no evidence of any research In the Oil companies inside the country but some researches have been tried to evaluate the effective factors on the social responsibility of other institutes such as Tehran municipal, Banks, broadcasting of Islamic Republic of Iran and automobile companies as follow:

1) Ali Taghavi and Mahdi HaghighiKaffash (2011) from Management College of Allameh Tabatabaei University, in their article entitled "Strategic performance of social responsibility among companies" have assigned a strategic condition for the content of social responsibility and provided a model with 5 aspects which covers other main aspects of this definition. These aspects are: 1. Legal responsibility 2. Meta-legal 
responsibility 3. Economical responsibility with a social performance 4 . Orienting to multiple stakeholders and 5 . Mixing the social responsibility with the organizational strategies (Taghavi \& HaghighiKaffash, 2011)

2) Saeid ArablaviMoghaddam (2012) from Economy College of Tabriz University in his thesis entitled "evaluation of the relationship between mission statement content and degree of corporates social responsibility" with the help of Naser Senovbar in 2012, has evaluated the presence of harmony between the attention to 4 stakeholders (customers, employees, local society and environment) and the degree of social responsibility of the companies due to these stakeholders and he has evaluated the role of variables modifying the corporate size, internationality and its ownership. Based on the purpose and the designed model, the multiple regression and hierarchy have been used to test the hypotheses.

The results of the statistical analysis have shown that there is no significant relationship between the consideration of these four stakeholders in the statements and the degree of social responsibility and considering these moderating variables doesn't lead to appearance of a significant relationship between dependent and in-dependent variables (ArablaviMoghaddam, 2012)

3) Saeid Mortazavi, Naser PourAzad, Pegah AmiriRazavi and Ma'soumeh Sadeghi Moghamdam (2010), in an article entitled "evaluation of the role of social responsibility modification on the relationship between social responsibility and organizational commitment in the companies in Mashhad" have reported that the modification of the social responsibility can affect the different aspects of social responsibility (including employees, customers, government, social and non-social stakeholders). It means that respecting the social responsibility and its observance by companies is a positive action impacting the organizational commitment of the employees (Mortazavi et al., 2010)

4) Samira maleki (2010) in her thesis entitled "evaluation of different aspects of social responsibility impacting the loyalty of the Sepah Bank's customers", by the support of Dr. Kambiz Heidarzadeh, has shown that the satisfaction with the relations and the customers' loyalty, the Bank's identity and the customers loyalty, the industrial performance of Sepah bank and satisfaction with relations and received industrial performance, moral behavior, trust and altruistic behavior with identification of them are directly related but there is no direct relationship between reliability on Sepah Bank and customers loyalty.

In fact, the study shows that the satisfaction with relationship and identity directly lead to consumers loyalty while social responsibility of the organization affects it indirectly. The moral aspect of social responsibility affects the delivered industrial performance and increases the customers' trust, while other-respecting behavior improves the identity of the customers in relationship with the Bank.

The findings show that the social responsibility affects the behavior of the consumer and his loyalty. So, the Bank's management should consider this issue (Maleki, 2010)

5) Zeinolabedin Amini (2010), from Science and research University, in his thesis entitled " designing a model to improve the social responsibility level in automobile companies" with support of Dr. Reza Najaf Beigi in 2010, has found out that the role of the top managers in the case of social responsibility has been very limited and that's why other factors related to social responsibility such as quality, believe in social responsibility, production control and quality level increase are not yet known. So, for improving the social responsibility level of the Saipa company, there should be some social responsibilities to pay attention to its importance and to make its quality as the main part of all fields (Amini, 2010)

6) The thesis of Masoumeh VaziriNezamDoost (2010) from Science and research University of Tehran entitled "evaluation of the factors impacting the social responsibility of public organizations of Iran" has been done with the support of Gholamreza Memarzadeh, Tehran (2010-2011).

The target of this research was to evaluate the social responsibility of Iran's public organization and to study the relationship between four effective factors including 1. Economic aspect, 2. Moral aspect 3. Social aspect 4. Environmental and social responsibility aspectof the organization.

The research method is a correlation method and the statistical society is a group of managers and professionals of power plan of Tarasht. Correlation test of Spearman and multi-linear regression method have been used for data analyzing. After collecting the data by using the questionnaires and through statistical analysis, it was found that the social responsibility of the managers and professionals is not desirable. Moreover all the independent variables of the economic, moral, social and environmental fields have a direct and significant relationship with social responsibility and the environmental variable is being considered as the most effective factor impacting the social responsibility. 


\section{Research Methodology}

\subsection{Hypotheses}

In this research, 7 hypotheses have been assigned to evaluate the significant relationship between each of these seven variables and the social responsibility and the $8^{\text {th }}$ hypothesis has been assigned based on the amount of the difference of each of these 7 factors on the social responsibility. The hypotheses are as follow:

1. There is a significant relationship between the corporate governance and social responsibility of the Oil and Gas extracting company

2. There is a significant relationship between the local society's improvement and social responsibility of the Oil and Gas extracting company

3. There is a significant relationship between the environmental protection and social responsibility of the Oil and Gas extracting company

4. There is a significant relationship between the doing fair activities and social responsibility of the Oil and Gas extracting company

5. There is a significant relationship between the consumer-related issues and social responsibility of the Oil and Gas extracting company

6. There is a significant relationship between the human rights observation and social responsibility of the Oil and Gas extracting company

7. There is a significant relationship between the working performance and social responsibility of the Oil and Gas extracting company

8. The coefficient of importance and the effects of these factors on the social responsibility of the Oil and Gas industry are different.

\subsection{Data Analysis}

The data have been analyzed based on the analysis of demographic and private data. The private data of explanatory statistics (Frequency, average percentage and standard deviation) and statistical samples have been used for data analysis.

\subsection{Questionnaires}

Table 1. Factors impacting corporate governance

1.1 Need of appropriate processes and decision structures in the field of social responsibility for responding to

1.1 the outcomes of the decisions and acts of the organizations

1.2 Providing appropriate environmental conditions for educating the principles of social responsibility

1.3 Balancing the needs of present generation, future generations and other stakeholders

Table 2. Factors impacting the local society

2.1 Before performing any developing plan, a consult should be done with the local society about the potential effects on them and reviewing the activities with the society

2.2 Participating in cultural activities of the society has to be done to improve the educational quality, local knowledge and to eliminate illiteracy

2.3 Before choosing the technology and investment, the effects of decisions on the employment have to be evaluated

2.4 Capacity building for employment. Attention should be paid to employment building or vulnerable groups

2.5 Participating in the development of new technology which may lead to solving of social and environmental issues in the local societies

2.6 Prioritizing the local suppliers of the products and their services and helping them Improving the health level in the local society like the ease of access to medications and vaccines. Using right

2.7 methods of having a healthy life like exercise, appropriate nutrition, early recognition of the illnesses, prohibition of using un healthy products and etc.

2.8 In planning the social investment projects, supporting the local development like increase in local purchase, outsourcing and etc.

2.9 Participation in the plans of access to food and other essential things for vulnerable groups. Local low-income people under discrimination 
A questionnaire with the principles of ISO 26000 , have been used to identify and rate the factors related to social responsibility of the organization. For doing so, we have studied the contents of ISO 26000 standard which includes 7 principles, 37 problems and 285 expected actions and then some related paragraphs have been combined together to reduce the number of the questions and those items that were not legal requirements, have been eliminated and those that were voluntary have been considered. At least, after 6 stages of questionnaire corrections and using the industrial consulting ideas and opinions, the advisor, had chosen 3 questions for the first hypothesis, 9 questions for the $2^{\text {nd }}$ hypothesis, 8 questions for the $3^{\text {rd }}$ hypothesis, 5 questions for the $4^{\text {th }}$ hypothesis, 7 questions for the $5^{\text {th }}$ hypothesis, 9 questions for the $6^{\text {th }}$ hypothesis and 8 questions for the $7^{\text {th }}$ hypothesis to find out the expected components affecting 7 principles of ISO 26000 standard.

Table 3. Factors impacting environment

3.1 Identification of different aspects and the effects of decisions on the environment and managing the pollutions

3.2 Participation of local and foreign stakeholders. Try to prevent the natural disasters and planning the needed and appropriate designs to overcome emergency events in or out of the organization

Improving the efficiency of the energy in order to optimize and increase energy efficiency, try to reuse the

3.3 consumed sources, identification of the best indices and criteria for measurement, control and evaluate the operation of the environment

3.4 Alteration or complementing the stable and low-impact non-renewable consuming resources using the solar energy instead of electrical power

Promoting the sustainability procurement including the purchase from the organization. Pay attention to

3.5 the environmental, social and moral performance of the product or service and prioritizing the incomes of the using products and services

Registration and reporting the green-house gases emission (like carbon dioxide, Nitrogen dioxide and

3.6 Methane) as the most important factors of changing the weather, by using the assigned methods by the measurement international standards and using appropriate tools to minimize the output of Greenhouse gasses directly and indirectly in the field of controlling them

3.7 Commodity purchase with high energy efficiency and improve using these services

Identifying the potential negative effects on ecosystem and biological diversity and try to eliminate or

3.8 minimize these effects to support the species or impressionable public habitats and those habitats that are potential to be effected by the organizational activities

Table 4. Factors impacting fair activities

4.1 Training the workers, industrial shareholders and constructors to improve their knowledge about corruption and ways of its elimination

Developing the policies and essential instructions to support the processes and procedures of the societies

4.2 and improve the knowledge of workers and organizational representatives about how to face the conflicts of interest and political partnership?

Developing processes and procedures of protection to protect the participation of anti-competition behaviors in the business

Using the moral, social, environmental criteria in the policy of the purchase, distribution and construction to improve the institutions compatibility and organization with the social responsibility

4.5 Assigning the society expectations, human rights, essential needs of people during protecting the rights of organization

Table 5. Factors impacting the consumers

\footnotetext{
Transparency in advertising and marketing, showing the key aspects of products quality and other essential

5.1 information. Non-participating in deceitful unfair activities and entering into ambiguous treaties and agreements with the consumers

5.2 Reducing the risks of the products and services by designing safe products, providing protective equipment and appropriate information to the consumer

5.3 To have a stable consume, to consider the products' life cycle, there is a need to eliminate or at least reduce and minimize the negative effects of the products and services on the environment and produce products
} 
with less negative effects on society and environment

5.4 Providing transparent information to the consumer about how to access to the after-sale services, supports, dispute resolution and compensation to consumers.

5.5 Limiting the personal data collection to use in producing necessary products and services by the voluntary agreements of the consumers

Managing the providing of services and products to all consumer groups fairly (if someone doesn't pay the

5.6 accounts on time and doesn't consider the appropriate paying time should not decrease the supply to the consumers).

5.7 Informing the consumers about different aspects of consuming like the risks and warnings, methods of compensation, effective consuming of materials and energy, eliminating the packings and etc.

Table 6. Factors affecting human rights

6.1 Developing a policy and a citizenship right (human right) to provide valid and significant advices to people who are in the organization or in a close relationship with that

Being in a specific position and condition (like involvement in extractive activities affecting natural

6.2 resources, being at the same level with local environments and etc.) inheritably would be challenged by the citizenship rights and there would be a need to effort for making sure of the accuracy of these rights

6.3 Being informed about environmental and social conditions of production and servicing and those products that would be bought as the raw material and the consumers condition

6.4 Providing compensation mechanisms to be used by the organization and stakeholders like fair, clear and easy getting mechanisms

Non-discriminating in providing the rights of employees, local citizens, shareholders, consumers or any

6.5 other person who is somehow related to the organization or can be affected by that (discrimination means making any kind of difference, sanction and preference which eliminates the equality and the advantage of opportunities)

6.6 Knowing the freedom of opinion and expression and avoiding overwhelm of opinions and ideas of people who perform in or out of the organization

6.7 Knowing the delivery and announcing the information and ideas in different methods and out of national borders

Respecting the economic rights of the employees (including appropriate job, appropriate life level, health and social freedom)

6.8 Social rights (including safety in the free-time and absence of transportations, sickness and disability, oldness and etc.), cultural rights (including religious activities and etc.) not performing in the inhibitory activities to stop, enjoyment of these rights

Accepting the principles and main rights related to the job that are provided by the international unions,

6.9 including social freedom, accepting the right of collective dialogue, eliminating forcing jobs, elimination of working children and elimination of discrimination in the relationship with employment

Table 7. Factors impacting the employees' performance

7.1 Non-profitable conservation through unfair activities, partners and constructors abuse (like employees' rights violation)

7.2 About those activities that are presented in in the international level attempts to recruit. Job development and development of people in the cost country

7.3 Respecting the family responsibilities and try to maintain a balance between work and life through making reasonable working hours, providing family leave policies and supporting the employees' children

7.4 Non-threatening and making an intimidating space in the condition where employees are interested in having responsibilities and having discussion

7.5 Attending to the risks related to the immune and safety of the people like pregnant women, disable employees, lactating women and employees without any experience

7.6 Supporting the safety rules and supporting part-time temporary and minor employees as like as others

7.7 Using the consulting services in all aspects to evaluate all aspects of the job's safety and health

7.8 Providing employees access to skills development, education and chance of job improvement fairly and without any discrimination 
After obtaining the approval of the questionnaires validity by experts and knowledgeable people in the field of social responsibility, the total of 49 questionnaires have been assigned for all of the hypotheses and 8 questions were assigned for testing the validation of the questions and the total number of questions was equal to 57 .

To measure and evaluate the respondents idea about each question the Lickert scale has been used, so, the effects of each question in the social responsibility field of the organization has been rated from 1-5 as strongly agree, agree, fairly agree, disagree and strongly disagree.

\subsection{Statistical Society and the Sample}

Since the organization was a corporation with an operational nature and it was a function of a related holding, corporate and some of the issues related to social responsibility has been performed in the field of holding companies activity. So, informing the respondents about the questionnaire was very important and had played an important role in protecting the results from being deviated. That's why the statistical society had been limited to top and middle stage managers. So the sampling method which had been used was a non- random and nonprobability sampling and in fact no sampling had been done and $\mathrm{N}=\mathrm{n}$ had been considered.

The sample size was equal to 42 managers. Researcher had gone to all meetings to introduce ISO26000 standards and give some information about the research. The managers had studied the strategies and perspectives of the organization based on its duty to evaluate the importance of each question and its relationship with societies to prioritize the factors that make a win-win relationship for the organization.

\subsection{Evaluation of the Data Normality, Their Reliability and Validity}

The evaluation of the distributed data's normality has been done by using the Clomogroph-Esmironoph test. The significance level for all the variables was more than 0.05 . So, the data were accepted as normal. There are several ways for evaluating the reliability of the work including: retest reliability, parallel reliability, validity of two halves of the question, logical consistency, and reliability between the questions by using the Cronbakh alpha (Hafeznia, 2012, p. 182)

The reliability has been assigned to evaluate the equality of reproducibility and correlation of questions by using the Cronbakh alpha method. The answers of 15 respondents from different statistical society levels have been measured by using SPSS. Since the calculated alpha was close to one so it can be said that the questions are similar and there is a good solidarity between the respondents. So the reliability of the questionnaires would be accepted as well.

\section{Results}

\subsection{Results of the Demographics}

The data of people who have answered the questionnaires in the statistical samples is as the followings:

1) $98 \%$ of the respondents were male and $2 \%$ were female. Based on the study, the Oil and gas extractive industry has an operational nature and a part of its activities is being done by the mother company in the south oil headquarters. So, based on the nature of the oil and gas extractive activity in the operational units, most of the managers were male.

2) More than $95 \%$ of respondents had a degree of license or higher. This shows that the managing and performing activities of the company are professional and the level of professional, social and cultural knowledge is high as well and the accuracy used can affect the way of problem solving.

3) More than $85 \%$ of respondents was at the age of 40 or higher. Since the sampling has been done among the managers, based on the age of the company we expect the managers to be old.

4) $22 \%$ of the respondents had a working experience of more than 30 years and more than $65 \%$ of them had an experience of 20 years or more. High level of age and experience in the field of management and knowledge about different issues is effective for providing specific rational responses and reaching appropriate results.

5) Since the questionnaire was related to all organizational offices, so all offices had participated in completing them.

6) The findings have shown that $12.2 \%$ of the respondents had been the top managers and $87.18 \%$ was medium level managers. Since, we need knowledge to participate in the field of social responsibility of the company, so the results of the recent samples are reliable and applicable. 


\subsection{The Results of the Pearson Test}

To evaluate the presence of the relationship between two quantifying variables, correlation coefficient of Pearson test has been used. This coefficient is between -1 and 1 , where the negative sign shows the diverse correlation and the positive sign shows the direct correlation between these two variables. So, as the absolute value of the correlation coefficient becomes more close to 1, the amount of the correlation will be increased and as it becomes close to zero, it shows that the correlation is weak. Moreover, it should be evaluated that how much the test is significant. The Pearson correlation coefficient, on the error level of 0.05 , has been used to evaluate the relationship between each of the 7 factors and the social responsibility of the company.

The results show that the $-p$ is smaller than $\alpha=0.05$. So, it can be said that there is a significant relationship between the variables and the social responsibility of the organization

Table 8. Results of variables correlation coefficient test and "social responsibility"

\begin{tabular}{llll}
\hline Frequency & Variable & Correlation coefficient & -P value \\
\hline 41 & Corporate governance & 0.477 & 0.002 \\
41 & Local society improvement & 0.691 & 0.000 \\
41 & Environmental protection & 0.417 & 0.007 \\
41 & Fair activity & 0.820 & 0.000 \\
41 & Consumer-related issues & 0.587 & 0.000 \\
41 & Respecting to human rights & 0.705 & 0.000 \\
41 & Employees working performance & 0.643 & 0.000 \\
\hline
\end{tabular}

\subsection{Results of Friedman Test}

The Friedman test has been used to compare and order the components of the study. This test would compare the variables' means and will evaluate the differences. In this test we rate the variables in each record and then we test the hypothesis of their equality by using the means of the variables.

Based on the results of the Friedman test, the variables have been rated. Then the titles of the actions and expectations have been rated for each of them. So, we can say that the components have been rated based on the 7 main topics. The results of this factors' rating, impacts the social responsibility of gas and oil extractive companies.

To simplify the understanding of these items, we have assigned a general topic for each of these questions and then all of these 7 factors have been provided in the table based on their importance. Those items that have less importance have been shown in gray.

As it can be seen, two principles of corporate governance and environmental protection are the most important factors affecting the social responsibility of the Gas and Oil extractive industries. Since these two numbers are close to what has been found in the Friedman hierarchy, so they would be placed in Group A and they would be considered as the organizational priorities. Based on the corporate governance's role, as the main stimulus of social responsibility in the organization and because of its importance and the responsibility of the managers in supporting its principles, two choices of corporate governance and environmental protection have been chosen as the most important factors impacting on the social responsibility of the company.

Three other principles including human rights, employees' working performance and the consumer-related issues have been chosen for the group $B$ and were placed at the $2^{\text {nd }}$ place of priority.

Two principles of local society's development and fair performing methods have been placed in group $\mathrm{C}$ and at the $3^{\text {rd }}$ stage.

Since the company is a performing and active company and performs under the related holding so some of the actions and expected expectations in the field of participating in the development of local society, has a more limited relation with the companies jurisdiction. Moreover the organization has no direct relationship in the field of competition and marketing. So, these two items have been placed in the $3^{\text {rd }}$ priority level. 
Table 9. Prioritizing the principles and independent components of social responsibility based on the mean scores of Friedman test

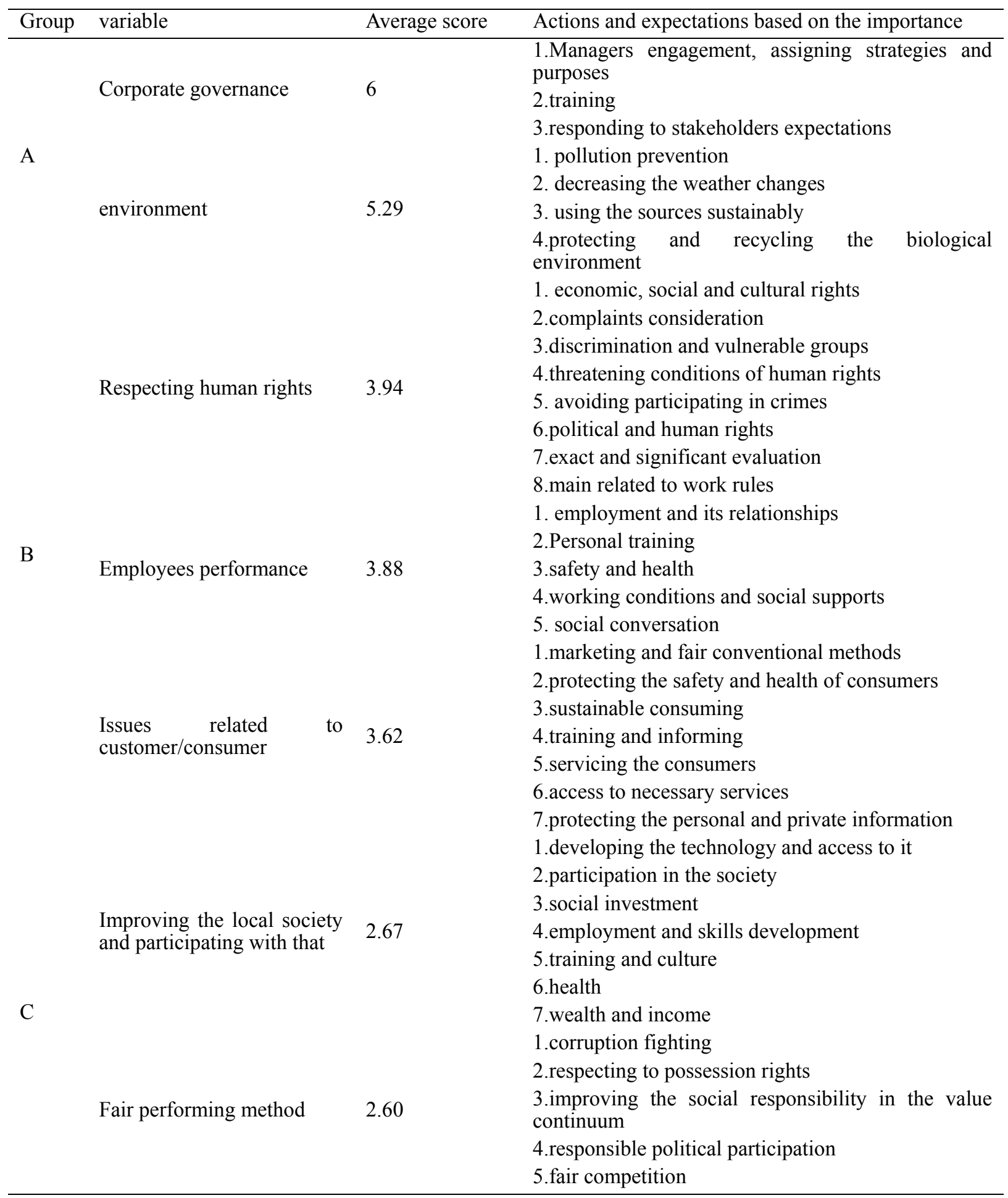

\section{Conclusion}

The study found that there is a significant relationship between 7 effective factors including 1.Corporate governance, 2. Environment, 3.Human rights 4.Employees performance, 5. Consumer-related issues, 6. Local society's improvements, 7.Fair performing methods, and the social responsibility of the extractive oil and gas industries. Corporate governance and environment have the most severe impacts on the social responsibility, respectively. 
Although in recent researches we didn't find any similar results with the results found in companies with the 7 effective factors, but Masoumeh VaziriNezamdoost (2010), from Science and Research University of Tehran, in her project entitled "evaluation of factors impacting the social responsibility of the public organizations in power plans in Iran" (2010-2011), tried to evaluate the relationship between four effective factors including economic aspect, moral aspect, social aspect and environmental aspect and the social responsibility. She has shown that there is a significant and direct relationship between the independent environmental variables and the social responsibility and this factor is the most effective factor impacting the social responsibility of power plan.

Based on the results of the data analysis which leads to the identification of effective factors impacting the social responsibility and initial factors of its structure, the following advices have been provided to be used for the social responsibility of the organization and other industries:

1. Holding training courses in the field of social responsibility to:

1) Improve the managers and employees' knowledge about how to make wealth by doing activities responsibly

2) Strengthening top and middle managers to identify the social response of the organizations appropriately and respond to the expectations of the stakeholders

2. Making a special working group to focus on the social responsibility of the organization and using the advices of consultants

3. Identifying the social problems of the local society and ordering them into 2 following groups:

1) Negative results of decisions and actions in the organization and planning to process them earlier

2) Public problems of local societies independently from the organizational activities that can be at the second level of support for its indirect effect on corporates activities in a way to make a common value and a relation of win-win without any inferences with other responsibilities of the organization

4. Creation of an appropriate field to mix the voluntary activities of social responsibility with the daily activities of the organization in the frame of its missions.

5. Making relationship with the promotion center of social responsibility. Developing the Iranian organizations and providing some news at the company level.

6. Being familiar with the performance of active companies at the international level in the field of social responsibility.

7. Strengthening the channels of communication with stakeholders to be familiar with different issues, expectations and needs of them as a base action in the system of social responsibility.

8. Focusing on the operating components of social responsibility with high priority and preventing the costs.

9. Knowing the NGO and people and trying to participate responsibly.

10. Voluntary organizational participating in one day in eighth of May each year.

11. Identifying the excess capacity over the organizational needs and using the opportunities and facilities by organization and local societies (like sport facilities, emergency clinics, fire stands and etc.)

12. Developing the principles of social responsibility in the field of its performance.

13. Transferring the findings to other gas and oil extractive companies that are under the Holdings based on the activities' similarities.

14. Evaluating the organizational performance in the field of social responsibility in the assessment center of Social responsibility promotion in Iran and identifying its strengths to improve the opportunities.

So, the following tips have been provided for future studies:

1) Designing a reporting system for the gas and oil extractive industries to report their performance.

2) Identifying the (negative and positive) effects of decisions and actions of the company

3) Identifying and rating the factors affecting the social responsibility of other organizations based on ISO 26000

4) Pathology of ignoring the social responsibility in different organizations

5) Evaluating the relationship between the social responsibility of the organizations and the globalization 


\section{References}

Amini, Z. (2010). Designing a model to improve the social responsibility level in the automobile companies in Iran. $\mathrm{PhD}$ thesis of public management. Islamic Azad university, science and research unit.

ArablaviMoghaddam, S. (2012). Study of the relationship between the degree of the corporate responsibility and mission statement content. MA thesis, Economic College of Tabriz University.

Costa, R., \& Menichini, T. (2013). A multidimensional approach for CSR assessment: The importance OF the stakeholder perception. Department of Enterprise Engineering, University of Rome Tor Vergata, Via Del Politecnico 1, 00133 Rome, Italy.

Hafeznia, M. (2012). Research methodology in humanities, Tehran, reading and editing humanity books, research and development unit of humanities.

Hilson, G. (2012). Corporate Social Responsibility in the extractive industries: Experiences from developing countries. School of agriculture, policy and development, the university of reading, early Gate, p.o. Box 237, reading rg6 6ar, UK.

Maleki, S. (2010). Evaluation of the effects of organizational social responsibility on the loyalty of customers in Sepah Bank. MS Thesis of business management, Azad University of Science and Research.

Mortazavi, S., Naser, P. A., Pegah, A. R., \& Masoumeh, S. M. (2010). Evaluation of the effects of the moderating role of social responsibility on the relationship between social responsibility and organizational commitment. Associate professor of Business Management, MS. Business Management, Ferdosi University of Mashhad.

Omidvar, A. (2012). ISO 26000 standard of corporate social responsibility. Tehran, Gandman.

Omidvar, A. (2013). Review of the organizations' social responsibility. Strategic researches unit of expediency. Retrieved from http://www.csriran.com

Spangler, I. S., \& Pompper, D. (2011). Corporate social responsibility and the oil industry: Theory and perspective fuel a longitudinal view. Temple University, Philadelphia, PA 19403, United States ISO 26000-Social responsibility. Retrieved from http://www.iso.org/iso/social_responsibility

Taghavi, A., \& HaghigiKaffash, M. (2011). The strategic performance of social responsibility in the companies. MA graduated student of MBA, $\mathrm{PhD}$ of business management.

VaziriNezamDoost, M. (2010). Evaluation of the factors impacting the social responsibility of public organizations in Iran. MS Thesis of Public Management. Islamic Azad University, Science and research unit.

\section{Copyrights}

Copyright for this article is retained by the author(s), with first publication rights granted to the journal.

This is an open-access article distributed under the terms and conditions of the Creative Commons Attribution license (http://creativecommons.org/licenses/by/3.0/). 